\title{
AN INVESTIGATION INTO THE PROPERTIES AND FABRICATION METHODS OF THERMOPLASTIC COMPOSITES
}

\author{
A Thesis \\ Presented to \\ the Faculty of California Polytechnic State University, \\ San Luis Obispo
}

\author{
In Partial Fulfillment \\ of the Requirements for the Degree \\ Master of Science in Materials Engineering
}

by

Ann Livingston-Peters

June 2014 
(C) 2014

Ann Livingston-Peters

ALL RIGHTS RESERVED 


\section{COMMITTEE MEMBERSHIP}

TITLE:

AUTHOR:

DATE SUBMITTED:

June 2014

COMMITTEE CHAIR: $\quad$ Blair London, $\mathrm{PhD}$

Professor of Materials Engineering

COMMITTEE MEMBER: Richard Savage, PhD

Professor of Biomedical Engineering

Director of Graduate Education

COMMITTEE MEMBER: Robert Weiss

Manager, Composite Bonding, Repair, and Thermoplastic Materials, Boeing Research and Technology 


\begin{abstract}
An Investigation into the Properties and Fabrication Methods of Thermoplastic Composites Ann Livingston-Peters
\end{abstract}

As applications for thermoplastic composites increase, the understanding of their properties become more important. Fabrication methods for thermoplastic composites continually improve to match designs specifications. These advanced thermoplastics have begun to show an improvement in mechanical properties over those found in thermoset composites commonly used in industry. Polyaryletherketones (PEK) have high service temperatures, good mechanical properties, and improved processing capabilities compared to thermoplastics used in the past making them important to the aerospace industry. The wide range of types of PEK make them suitable for a variety of applications, but selection of specific chemistries, processing parameters, and composite stack-ups determine the mechanical properties produced. Differential scanning calorimetry (DSC), and Fourier transform infrared spectroscopy (FTIR) were used to determine crystallinity and chemical properties of several polyaryletherketones. Tensile, compressive, and Mode I interlaminar fracture toughness tests were conducted to analyze mechanical properties of these advanced thermoplastics. Several fabrication processes were also tested to determine optimal consolidation and aesthetic appearance of structural members. All testing was conducted at The Boeing Company in Seattle, Washington. Because all testing and conclusions are proprietary a general synopsis of the experience will be presented.

Keywords: thermoplastics, composites, carbon fiber, polymer, non-destructive imaging, mechanical testing, materials engineering. 


\section{ACKNOWLEDGMENTS}

This thesis was made possible by The Boeing Company and manager Robert Weiss of the Composite Bonding, Repair, and Thermoplastic Materials group of Boeing's Research and Technology division. I would like to thank Robert Weiss for his willingness to bring on a co-

op/thesis student to work in his group. I would also like to thank Professor Blair London for his continued support and willingness to be my advisor. Professor Richard Savage is also responsible for making this opportunity possible. 


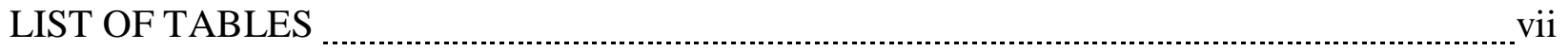

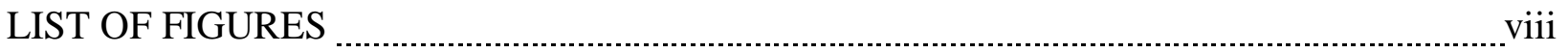

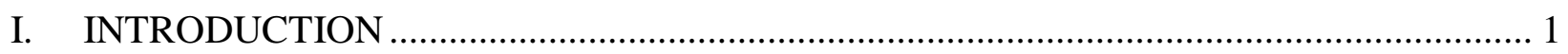

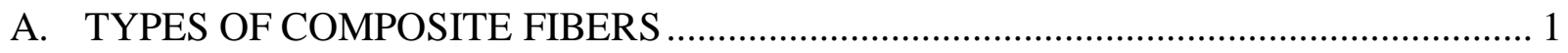

B. TYPES OF COMPOSITE MATRIX MATERIALS ............................................... 6

1. THERMOSETTING POLYMERIC MATRICES ..................................................... 6

2. THERMOPLASTIC POLYMERIC MATRICES ................................................... 7

C. COMPOSITE FABRICATION METHODS ........................................................ 8

D. COMPOSITE TESTING METHODS .................................................................... 9

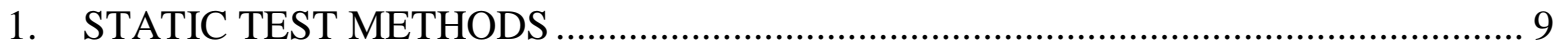

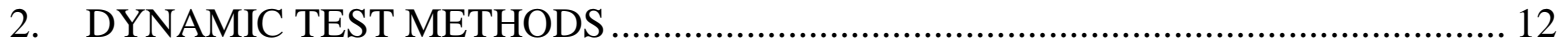

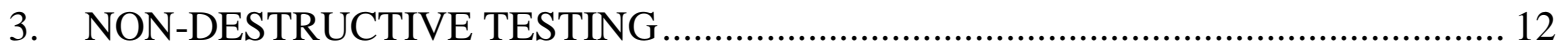

II. POLYARYLETHERKETONES .......................................................................... 15

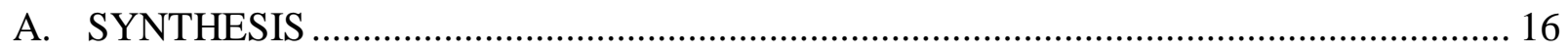

B. THERMOPLASTIC COMPOSITE MATERIAL FABRICATION ............................. 17

C. THERMOPLASTIC COMPOSITE PART FABRICATION ...................................... 18

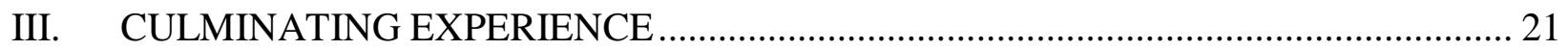

A. COMPOSITE FABRICATION AND LABORATORY EXPERIENCE........................ 21

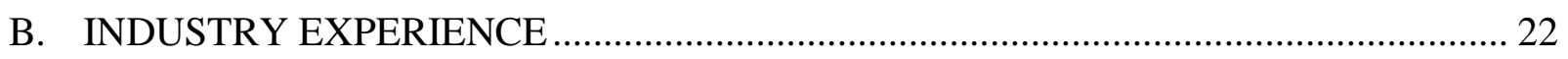

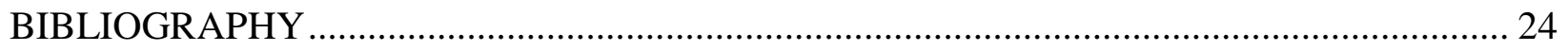




\section{LIST OF TABLES}

Table \#

Page

Table I: Properties of various non-reinforced matrix materials............................................ 8 


\section{LIST OF FIGURES}

Figure \# Page

Figure 1: Three most common fibers used in composite applications ${ }^{2}$........................................ 2

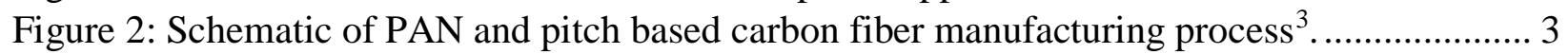

Figure 3: Comparison of weave types: Plain, harness satin, and twill ${ }^{4}$...................................... 4

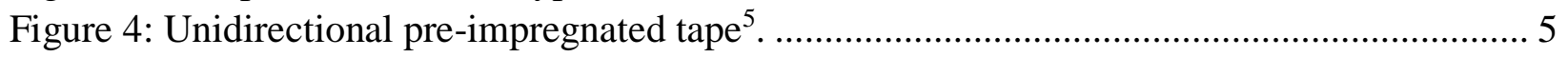

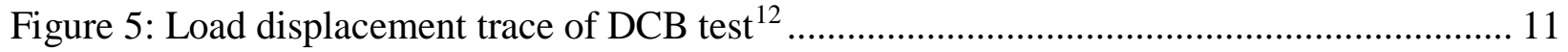

Figure 6: Fracture resistance spread determined from VIS and NL readings.............................. 11

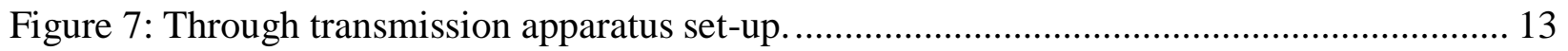

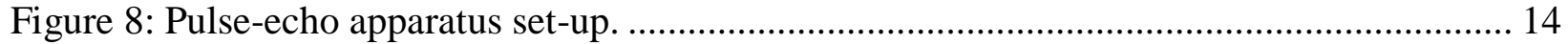

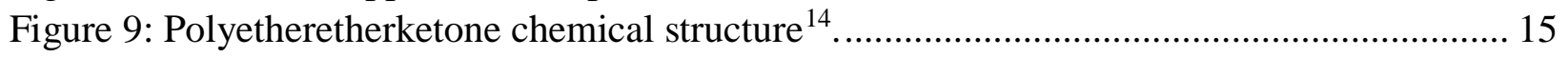

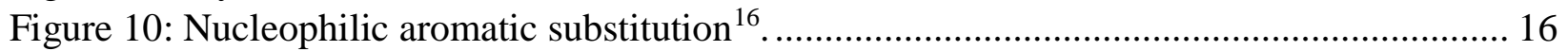

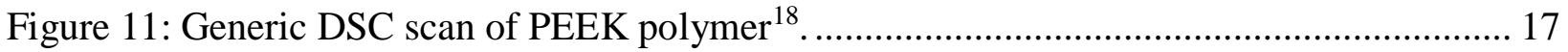

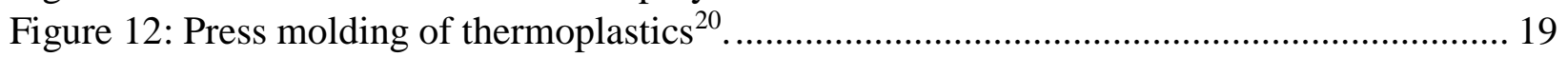




\section{INTRODUCTION}

Composite materials are growing in the number of applications utilizing them as improvements are made to manufacturing techniques and availability of raw materials. Composites consist of two parts: a matrix and a reinforcing material. The matrix is designed to transfer the load to the reinforcing material (fibers), to protect the fibers, maintain the fiber orientation, and keep the fibers separated from one another. The reinforcing material is designed to carry the load and provide the strength and stiffness required for structural applications. There are many advantages and disadvantages of composites, depending upon the application these attributes will vary. In general, composites are lightweight, have high specific stiffness and strength, are easily moldable to complex shapes, have good fatigue resistance, and have low thermal expansion ${ }^{1}$. These advantages make composites an optimal material choice for advanced applications. However, composites are expensive and require extensive design and analysis time due to minimal well-proven design rules. Temperature limits, damage susceptibility, low ductility, and manufacturing times are factors to consider when designing with composites. The following sections give background into composites their fiber types, matrix types, common tests and fabrication methods. More specifically, thermoplastic composites will be discussed with regard to fabrication, mechanical properties, and chemical properties.

\section{A. TYPES OF COMPOSITE FIBERS}

Composite materials are widely used due to their high strength-to-weight ratio as well as their high modulus-to-weight ratio. Composite mechanical properties can be tailored specifically to each design application. There are three widely used reinforcing materials: carbon fiber, glass fiber, and Kevlar fiber all having unique properties (Figure 1). 


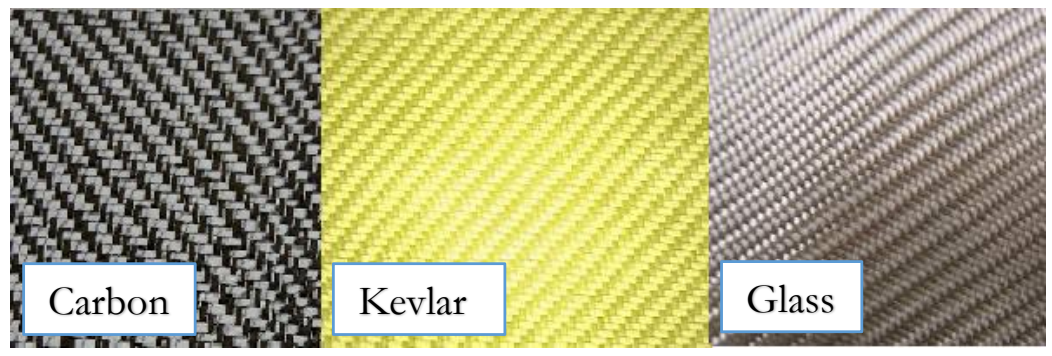

Figure 1: Three most common fibers used in composite applications ${ }^{2}$.

Glass fibers are the most commonly used fibers in a polymer matrix composite due to their low cost, high tensile strength, electrical and thermal insulating properties and chemical resistance. Glass fibers however have a low tensile modulus, have a high density compared to other fiber types, are hard, and have a low fatigue resistance. Glass fibers are typically formed from long chains of $\mathrm{SiO}_{4}$ tetrahedrons that are melted, extruded, drawn, and coated with sizing before use. Another disadvantage of glass fibers is there susceptibility to fatigue from water if not properly encased in matrix material.

Carbon fibers are the second most widely used reinforcing material with growing popularity. Having a high tensile strength-to-density ratio as well as high modulus-to-density ratio carbon fibers are used in many aerospace and technical applications. Carbon fiber also has low linear thermal expansion, high fatigue strength, and a high thermal conductivity. Carbon fiber has relatively high electrical conductivity which can be a disadvantage in many applications, but an advantage in some. Other disadvantages to carbon fiber are its low strain to failure, low impact resistance and its high cost. Carbon fiber can be manufactured in two ways as shown in Figure 2: using polyacrylonitrile (PAN) or pitch. PAN carbon fiber is processed in three phases, the first phase, stabilization forms the carbon structure, the second phase, carbonization determines the composition, and graphitization changes the orientation of the 
graphite structure. Pitch carbon fiber is a meso-phase in which it is first melt spun then it goes through the same three steps as PAN. Pitch carbon fiber is more easily graphitized giving it a higher modulus than PAN.

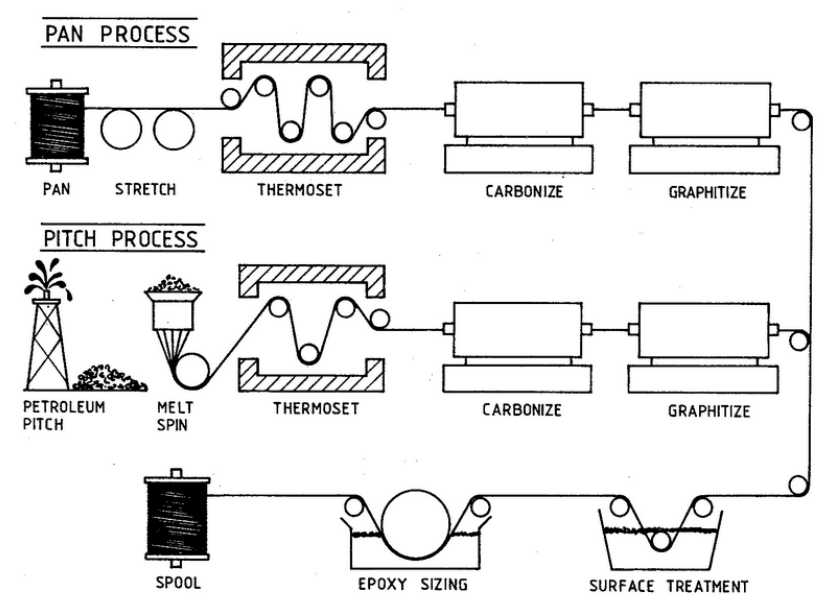

Figure 2: Schematic of PAN and pitch based carbon fiber manufacturing process ${ }^{3}$.

Aramid fibers, most commonly attributed to Kevlar are advanced fibers that utilize aromatic polyamides. Nylon is considered an aramid fiber, but is a generic name for a long chain of polyamides. Kevlar however is a specific network polyamide manufactured from parasubstituted aromatic units that is formed from two processes. The first process is a condensation reaction in which para-phenylene diamine and terephthaloyl chloride are reacted to produce poly-p-phenylene-terephalamide (PPDT). The PPDT then undergoes an addition reaction to produce linear polymers linking the PPDT mer units. This precursor PPDT, a nematic liquid, contains the structure of the molecular chains which is then extruded through a spinneret. The extrusion process forms sheets of molecules that are radially arranged and axially pleated due to bonding. Kevlar is known for its toughness and its ability to absorb energy. Because Kevlar is highly oriented, weak hydrogen bonds are formed to adjacent molecules making it highly anisotropic. 
There are many different types of reinforcement forms into which fibers can be arranged. These fiber forms have specific applications and purposes due to the importance of the reinforcement on final properties. Each form of reinforcement also plays an important role in the type of processing required. The fibers are initially made into filaments through a process called spinning, when thousands of fibers are gathered in an untwisted manner they are drawn into tows or rovings. These tows can be oriented in woven fabrics or aligned longitudinally to form unidirectional tapes. Fabrics have been developed from textile patterns for various handling and mechanical properties. Fabrics can have a variable openness, or space between the fibers, and variable drape, the ability to hang without creasing. The simplest weaving pattern is plain weave which is made from interlacing strands in an alternating over under fashion (Figure 3). The second most common weave pattern is twill weave which has the appearance of diagonal lines due to the over one under two pattern. There is also basket weave, crowfoot weave, leno weave, and harness satin weaves for various applications based upon the ability to drape and wetting properties.

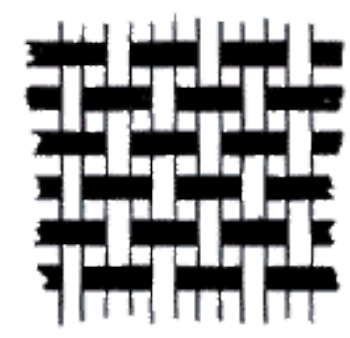

Plain Weave

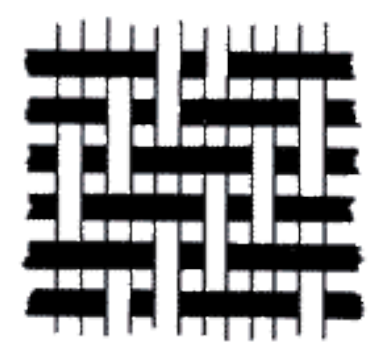

2/2 Twill Weave

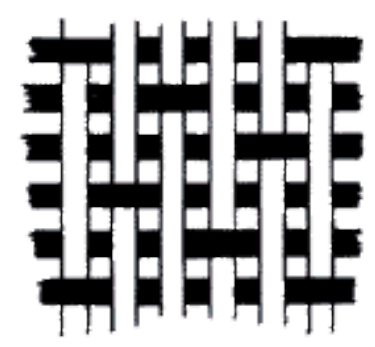

5-Harness Satin Weave

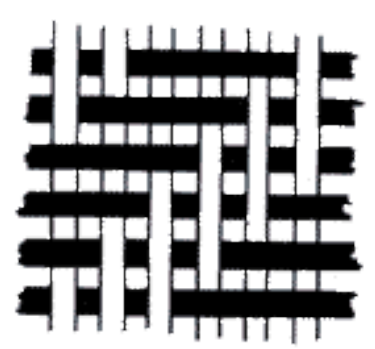

3/3 Twill Weave

Figure 3: Comparison of weave types: Plain, harness satin, and twill ${ }^{4}$. 
If the application does not require the sophistication of a woven reinforcement, nonwoven fabrics called mats can be used. Non-woven fabrics are less expensive and less precise with lower mechanical properties than a woven fabric would have for the same application. Chopped strand mats can be used for producing simple less durable products where technical fabrics are not needed. Chopped strand mats are sheets of material made by chopping tows of fibers into small lengths and by joining them together using a binder. Continuous strand mats can also be used for similar applications. Continuous strand mats have longer strands of material than the chopped mat and therefore have improved mechanical properties.

For advanced reinforcements where precision and care has to be taken for orientation, pre-pregs are used. For applications where the majority of the load will be taken in one direction another method has been developed to optimize fiber orientation. Unidirectional tapes are now produced to be used in such applications. Unidirectional tape has all of the fibers oriented in one direction, along the length of the roll as shown in Figure 4. These fibers are coated in the desired final resin amount so no additional resin needs to be added during fabrication. This method forms pre-pregs, or pre-impregnated tapes and fabrics that already contain matrix material. The resin coating in pre-preg sheets is typically epoxy in a B-stage (partially cured) state.

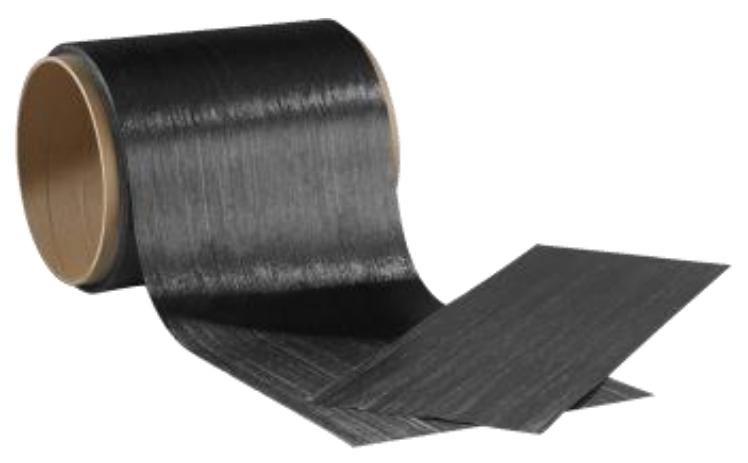

Figure 4: Unidirectional pre-impregnated tape ${ }^{5}$. 


\section{B. TYPES OF COMPOSITE MATRIX MATERIALS}

Composites matrix materials are chosen and designed to protect the fibers from the environment, maintain the fiber orientation, transfer the load to the fibers, and to separate the fibers away from themselves. There are many different types of matrix materials from polymeric to ceramic to metallic. Each type of matrix is chosen based upon its specific properties and how the matrix reacts with the reinforcement.

\section{THERMOSETTING POLYMERIC MATRICES}

Thermosets are typically liquid resins at room temperature. This liquid resin is then applied to a mold or a material for curing. The curing process takes place as bonds form and heat is present. These bonds or crosslinks change the basic nature of the material changing the once liquid resin into a solid material. Once cured the thermoset can no longer be melted. Thermoset polymers have sites along the polymer chain that can be activated to become reactive. These sites react in a way that chemical bonds are formed between adjacent polymer molecules. This crosslinking formation is what cures the material and hardens it. When crosslinks form they restrict the motion of the polymer molecules to an increasingly greater amount. There are several disadvantages to thermosets, including: processing time, vapors, limited shelf life, inability to reprocess, and poor toughness.

The most common type of matrix material is a polymer. In a polymer matrix, single molecular units called monomers are linked together into short chains called oligomers that are then bonded together leading to a polymer molecule. Many variations of polymeric matrices exist for predetermined properties. Some common thermosets include polyester, vinyl ester, epoxy, polyimide, phenolic, and cyano-acrylate. Polyester resin is the cheapest and most widely 
used matrix in conjunction with fiberglass. The curing of polyester is typically initiated with small quantities of catalyst; the catalyst most often used is a type of peroxide, such as methylethylketone peroxide (MEKP) ${ }^{6}$.

Epoxies are the second most common thermosetting polymeric matrix materials. Epoxies are used in many applications other than composites such as coatings and adhesives. Epoxy is also used in circuit boards due to its low electrical conductivity and high dielectric strength. Epoxies are formed from an oxirane group which is where crosslinking occurs. Epoxy has excellent adhesion, shear strength, fatigue resistance, strength and stiffness when compared to polyesters. Epoxy is most commonly paired with carbon fiber while polyester and fiber glass are a common combination. The increased mechanical properties of epoxy are directly related to an increase in cost.

\section{THERMOPLASTIC POLYMERIC MATRICES}

Thermoplastic composite materials are becoming more popular and have increased properties making them used in an increasing number of applications. Structural thermoplastics in particular have become a prevalent alternative to thermosets due to their enhanced mechanical properties, differences in processing capabilities, and manufacturing benefits ${ }^{8}$.

Thermoplastic resins are solid at room temperature and are processed significantly differently than liquid thermoset resins. With adequate pressures parts are fabricated with low void content and can be recycled. Thermoplastic composite have the added benefit of being able to be stored at ambient temperatures, so no refrigeration is necessary. Thermoplastics are heated and softened for application into a mold and then allowed to cool into the new shape. Some common aerospace grade thermoplastics include polyetheretherketone, polyetherketoneketone, and 
polyetherimide. Even after being formed the first time, thermoplastics can be reformed. The ability to reform and reshape parts is beneficial in many applications, but care needs to be taken to make sure temperatures are adequate for the design.

Thermoplastics do not have crosslinks and therefore can be reprocessed. In the heating process of thermoplastics there is no change in molecular weight which can compromise mechanical properties ${ }^{6}$. With the increase in molecular weight in thermosets the mechanical properties also increase (Table I). In thermoplastics the increased molecular weight makes processing increasingly difficult due to increased melting temperatures. However, thermoplastics have increased fracture toughness making them a desirable candidate for aerospace applications.

Table I: Properties of various non-reinforced matrix materials.

\begin{tabular}{|c|c|c|c|c|c|}
\hline Property & Polyesters & Epoxies & Polyimides & Phenolics & Thermoplastics \\
\hline Maximum Use & $175-285$ & $200-350$ & $400-600$ & $300-400$ & $340-450$ \\
Temperature ${ }^{\circ} \mathrm{F}\left({ }^{\circ} \mathrm{C}\right)$ & $(79-141)$ & $(93-177)$ & $(204-316)$ & $(149-204)$ & $(171-232)$ \\
\hline Density $(\mathrm{g} / \mathrm{cc})$ & $1.1-1.2$ & $1.2-1.25$ & $13-1.4$ & $1.3-1.4$ & $1.1-1.2$ \\
\hline Tensile Strength & $3-13$ & $5-15$ & $6-13$ & $5-9$ & $5-20$ \\
ksi (MPa) & $(21-89)$ & $(34-103)$ & $(41-89)$ & $(34-62)$ & $(34-138)$ \\
\hline Tensile Modulus & $0.3-0.6$ & $0.6-0.7$ & $0.5-0.6$ & $0.8-1.7$ & $0.3-0.7$ \\
Msi (GPa) & $(0.2-0.4)$ & $(0.4-0.5)$ & $(0.3-0.4)$ & $(0.6-1.2)$ & $(0.2-0.5)$ \\
\hline Moisture Absorption $(\%)$ & $0.15-0.6$ & $0.1-0.7$ & $1.1-1.2$ & --- & $0.01-0.3$ \\
\hline
\end{tabular}

\section{COMPOSITE FABRICATION METHODS}

Various applications of composites require their own fabrication methods. For semi-complex shapes or where production rates are low hand layups are utilized. During a hand layup dry material is applied with resin or pre-preg is utilized to fabricate parts. For parts fabricated with pre-preg an autoclave is used for curing the parts. Compression molding techniques are used to transform sheet molding compounds into finished products between matched metal molds. Compression molding can yield complex geometries in short periods of time while reducing 
finishing operations. Compression molding can be made automated allowing for higher production rates. Pultrusion is used to produce long, straight structural members of constant cross-section. Filament winding utilizes a band of continuous roving impregnated with resin that is then wrapped around a rotating mandrel and allowed to cure. Another low production rate method of fabricating composite parts is resin transfer molding (RTM). RTM utilizes a two sided mold in which catalyzed resin is injected and pulled through the cavity containing fibers to form a part.

\section{COMPOSITE TESTING METHODS}

Testing can be conducted to help understand mechanical and physical properties of composites. Physical properties of the individual components can be tested in a variety of manners to determine viscosity, draping properties, tack properties, glass transition temperatures and void content. In designing for composite applications mechanical testing is necessary to understand specific loading conditions seen in each application. Composites vary tremendously between applications and mechanical testing to determine tensile, compressive, flexural, torsional, and shear properties is necessary ${ }^{7}$. Static and vibratory tests can be conducted to determine mechanical properties of composites.

\section{STATIC TEST METHODS}

Tensile properties can be determined using ASTM D3039 ${ }^{9}$ which is a tensile test for resinmatrix composites reinforced by oriented continuous or discontinuous high modulus fibers. Factors that influence the results of this test include: material, material preparation and layup, ply stacking sequence, specimen preparation, alignment and gripping, speed of testing, and void 
content ${ }^{9}$. The ultimate tensile strength and strain, the modulus of elasticity, and Poisson's ratio can be determined using this test method.

Flexural and shear properties are determine in a bend testing apparatus. The standard flexural test method used is a three point method where a beam is loaded from the center and supported on either end. ASTM D790 ${ }^{10}$ is use to determine the flexural properties of reinforced plastics, including high-modulus composites.

To determine delamination growth and Mode I fracture toughness, ASTM D6115 ${ }^{11}$ Standard Test Method for Mode I Fatigue Delamination Growth Onset of Unidirectional Fiber-Reinforced Polymer Matrix Composites and ASTM D5528 ${ }^{12}$ Standard Test Method for Mode I Interlaminar Fracture Toughness of Unidirectional Fiber-Reinforced Polymer Matrix Composites were used. D6115 determines the number of cycles for the onset of delamination growth based on the opening Mode I cyclic strain energy release rate, using the Double Cantilever Beam (DCB) specimen. D5528 describes the determination of the opening Mode I interlaminar fracture toughness, GIC of continuous fiber-reinforced composite materials using DCB coupons (Figure 5). Since thermoplastics inherently have higher fracture toughness these tests were conducted to determine design criteria. 

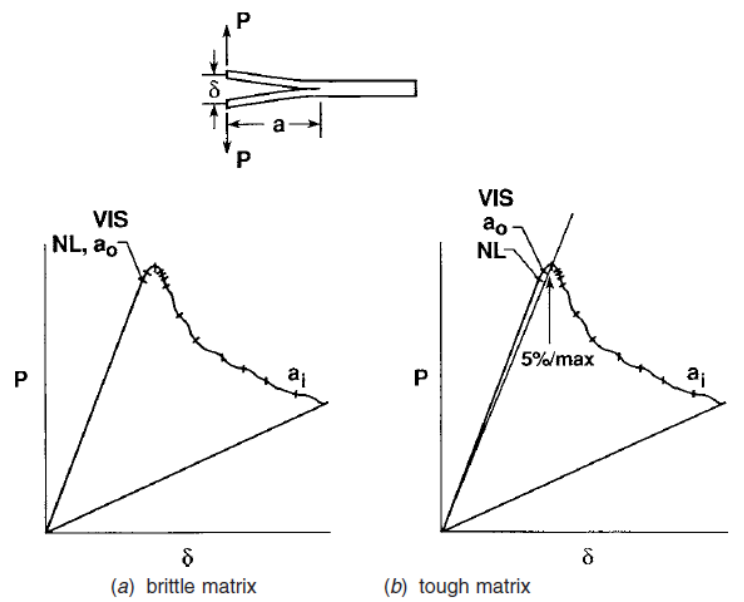

Figure 5: Load displacement trace of DCB test ${ }^{12}$

The visual onset (VIS) value is obtained through the load displacement curve corresponding to a visual propagation of the crack front at the edge of the DCB specimen. This value typically yields a higher estimation of the $\mathrm{G}_{\mathrm{IC}}$ because damage occurs prior to visual detection (Figure 6). The point at which the load-displacement curve becomes non-linear (NL) is the final and most conservative determination of GIC.

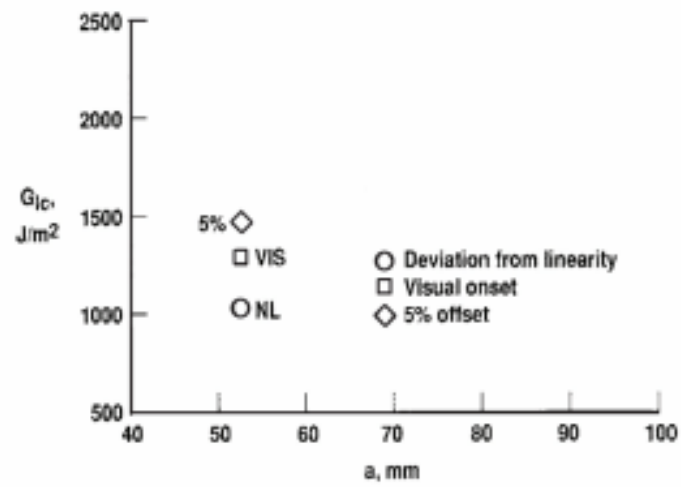

Figure 6: Fracture resistance spread determined from VIS and NL readings. 


\section{DYNAMIC TEST METHODS}

Vibrations through a composite can be detrimental to its strength. As vibrations travel through the material they can cause fiber-matrix bond breakage as well as delamination. The initiation of micro-cracks can also be caused by vibrations which lead to fatigue and failure over a period of time.

Fatigue testing is another form of dynamic testing in which a load just under the ultimate is applied over long periods of time in a cyclic method. During a fatigue test an intermittent load is

applied cyclically over long-periods of time. After a set number of cycles the critical property to be determined is re-measured. Carbon composites have improved fatigue performance than some metallic counterparts. Composites stabilize early in the life of the product by several different mechanisms. Micro-cracking, crack-tip blunting, delaminating, and stress redistribution all allow composites to absorb energy without failing reducing the effects of fatigue.

\section{NON-DESTRUCTIVE TESTING}

While destructive testing is informative and can be used to help understand performance under loading, final parts need to be inspected without reducing the integrity of the part. ASTM E2580-12, the Standard Practice for Ultrasonic Testing of Flat Panel Composites and Sandwich Core Materials Used in Aerospace Applications ${ }^{13}$ outlines the specific process needed to accurately image and test composites using ultrasound. Ultrasonic testing is a common method for detecting discontinuities within a laminate. Specific anomalies found using ultrasound include foreign materials, delamination, disband/un-bond, fiber de-bonding, inclusions, porosity, and voids. Ultrasonic frequencies of $20-100 \mathrm{MHz}$ are prone to being affected by changes in 
density making them useful for inspection. The wavelengths are of similar sizes to the size of common defects. When a wave interacts with porosity or a defect the changes in density from the base material and that of the problem area changes the signal dramatically.

Two techniques can be considered depending upon panel geometry. Through transmission is used for two sided panel access and pulse-echo for one sided access. Ultrasonic through transmission testing is a simple imaging method which utilizes ultrasound (Figure 7). A receiver and transmitter are first placed on opposite sides of a part and then a signal is pulsed between the two devices. As the two devices are moved across the part they monitor the changes in signal. To reduce the amount of noise in the test the entire set up is immersed in water to help attenuate the waves through to the part.

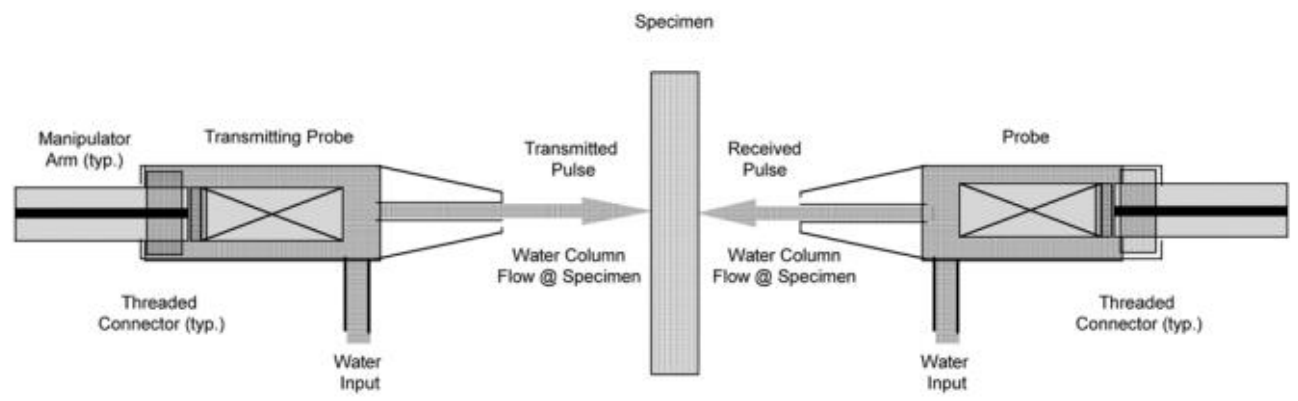

Figure 7: Through transmission apparatus set-up.

Pulse-echo testing is another imaging process in which an ultrasonic signal is transmitted into a part (Figure 8). During pulse-echo imaging however, the signal is transmitted into the part and then is reflected off the backside of the part. Defects are found in this method by the faster return of the signal than if the signal traveled through the entire part. 


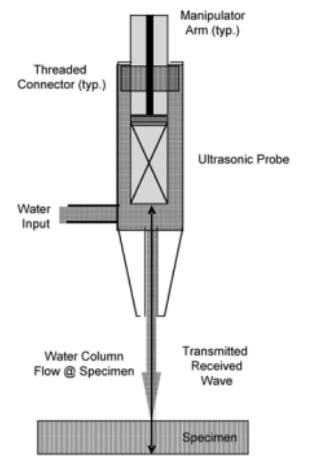

Automated

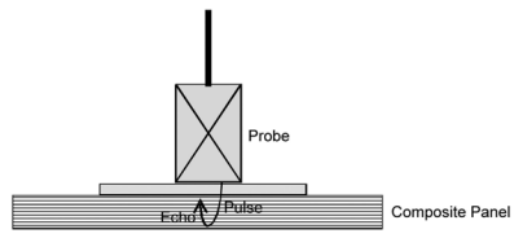

Manual

Figure 8: Pulse-echo apparatus set-up. 


\section{POLYARYLETHERKETONES}

High performance thermoplastics have an added degree of aromaticity increasing stiffness, strength, flame-retardant properties, and high thermal stability to the backbone of the polymer. These properties make it commonly used in aerospace applications. Polyetheretherketone (PEEK) is one of the most commonly used advanced thermoplastics due to mechanical, thermal, and chemical stability (Figure 9).

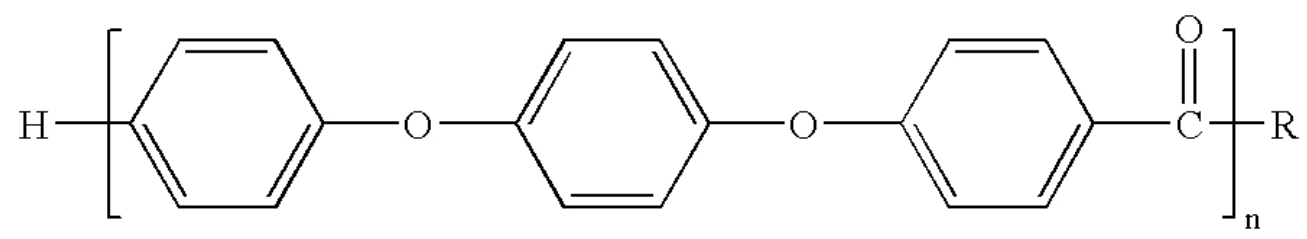

Figure 9: Polyetheretherketone chemical structure ${ }^{14}$.

Several types of thermoplastics follow a similar structure as PEEK such as polyetherketones (PEK) and polyetherketoneketone (PEKK). PEEK, PEK, and PEKK have similar properties and are typically grouped together and referred to as polyaryletherketones with aryl alluding to the high aromatic content. PEEK has an increased glass transition temperature due to the highly aromatic chains which give it low flammability, low electrical conductivity, high solvent resistance, high strength, and excellent toughness ${ }^{15}$. PEEK has a high degree of crystallinity and is considered semi-crystalline. This crystallinity leads to structural rigidity, high strength, and high modulus. PEEK is one of the most widely used thermoplastics in the aerospace industry and therefore has the most data available making it easier to integrate into a design. PEEK's popularity can also be attributed to its thermal stability and processing characteristics. With a modulus around $3.2 \mathrm{GPa}$, and service temperatures near $250^{\circ} \mathrm{C}$ PEEK is an ideal candidate for aerospace applications. 


\section{A. SYNTHESIS}

Aromatic nucleophilic substitution reactions of activated aryl dihalides with aromatic diphenolates is a general synthesis process for polyaryletherketones (Figure 10). This synthesis is typically performed in a dipolar aprotic solvent, or by electrophilic acylation of aryl ethers.
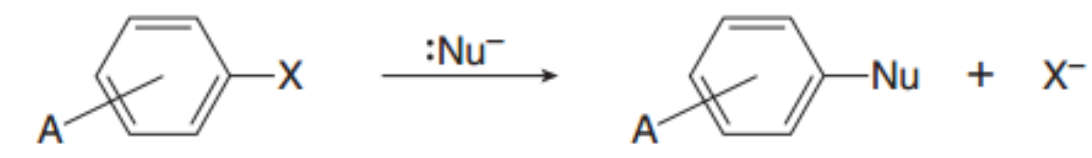

$\mathrm{X}=\mathrm{F}, \mathrm{Cl}, \mathrm{Br}, \mathrm{I}$

$\mathrm{A}=\mathrm{H}$ or electron-withdrawing group

Figure 10: Nucleophilic aromatic substitution ${ }^{16}$.

To maintain solubility during processing, the reaction takes place near the melting temperature of the polymer. At such high temperatures side reactions take place, such as an ether exchange and bond cleavage. These processing techniques have been further developed and optimized to yield high molecular weight polyetherketones. PEEK's high nucleation density allows the polymer to crystalize during cold and melt crystallization. Differential scanning calorimetry (DSC) can be used to accurately determine the crystallinity of PEEK by analyzing the melting trace to gain the heat of fusion (Figure 11). 


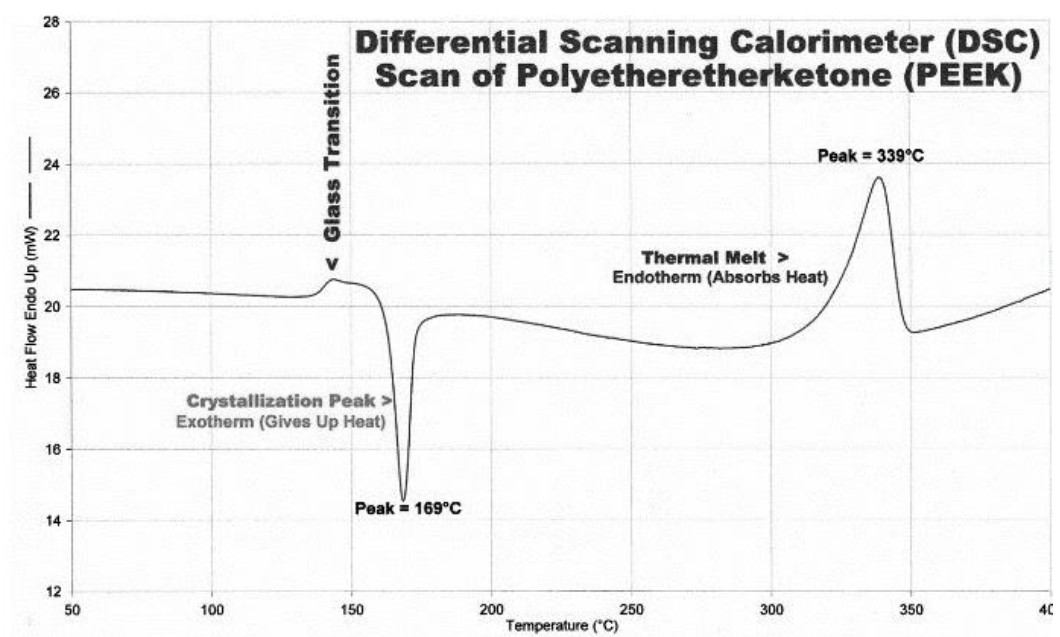

Figure 11: Generic DSC scan of PEEK polymer ${ }^{18}$.

The heats of melting and cold crystallization can be determined by integrating the areas under the peaks. The percent crystallinity is then determined using equation one ${ }^{17}$.

$$
\left.\% \text { Crystallinity }=\left(\Delta \mathrm{H}_{\mathrm{m}}-\Delta \mathrm{H}_{\mathrm{c}}\right) / \Delta \mathrm{H}_{\mathrm{m}}^{\circ} * 100 \% \quad \text { (Equation } 1\right)
$$

Where, $\Delta \mathrm{H}_{\mathrm{m}}$ is the heat of melting in joules per gram, $\Delta \mathrm{H}_{\mathrm{c}}$ is the heat of cold crystallization in joules per gram, and $\Delta \mathrm{H}^{\circ}$ m is the pre-calculated reference value assuming $100 \%$ crystalline. The $\Delta \mathrm{H}^{\circ} \mathrm{m}$ for PEEK is $130 \mathrm{~J} / \mathrm{g}$.

\section{B. THERMOPLASTIC COMPOSITE MATERIAL FABRICATION}

Thermoplastic composites require special processing techniques versus those commonly used for thermoset composites. Since thermoplastics have a relatively high melting, glass transition, and service temperature, care must be taken to properly heat, soak, and cool each part. Due to the high molecular weight of thermoplastics once melted they have a high viscosity making them difficult to wet into the reinforcing fibers. Methods have been developed to lower the viscosity 
including higher processing temperatures, adding a solvent, and shearing the polymer during processing. The smaller the reinforcing material the easier fiber wet out becomes. Pellets of thermoplastic and short fibers can be manufactured for injection and compression molding. Although processing short fibers is simpler, the longer the reinforcement the higher the strength. For aerospace applications where an increased strength is necessary continuous fiber thermoplastic composites are in the form of sheets and rolls of thermoset pre-preg-like material.

Semi-preg, or thermoplastic pre-preg, is fabricated from woven sheets of carbon fiber that have been laminated with thin sheets of thermoplastic polymer. This method is similar to thermoset pre-pregs, but has continued issues with fiber wet out. New methods of powder coating thermoplastic polymer onto the surface of woven or unidirectional reinforcements has shown an improvement in fiber wet out ${ }^{6}$. With increased fiber wet out rapid thermoforming to net part shape can meet higher production volumes. Another method for fiber wet-out is coweaving. In co-weaving or co-mingling the reinforcing fibers are woven together with the matrix material with one being the warp and the other the weft. This method allows cloth, preforms, braids, and knits to be made utilizing highly developed textile technology. The different weaves available would allow for tailoring of drapability and increased ease of part fabrication.

\section{THERMOPLASTIC COMPOSITE PART FABRICATION}

Various methods exist for processing of pure thermoplastics in which a few have been converted for use with thermoplastic composites ${ }^{19}$. Extrusion is one of these processes that work for neat plastic or composite part manufacturing. Extrusion utilizes a die that is shaped in the cross-section of the desired product. Short fiber thermoplastic composites are used during 
extrusion. When more complex shapes are desired an injection molding technique can be utilized. Processes have been adapted from thermoset processing to function for thermoplastics such as open molding techniques, filament winding, pultrusion, and compression molding which were briefly discussed in the Composite Fabrication Methods section.

The newest development in thermoplastic composite fabrication molding techniques is the use of preheated thermoplastic composite sheets which are then press formed between two matched molds. The sheets are laid up in the final part configuration and are pre-consolidated. If orientation is of great importance the sheets will be fully consolidated to minimize slipping of sheets during pressing. These sheets, or blanks are then heated to the softening point or sag point of the thermoplastic. By softening the plastic the part will flow into the mold cavity more efficiently as well as reduce the amount of needed pressure. Once the blanks are thoroughly heated to this sag point it is shuttled into a matched mold as shown in Figure 12.
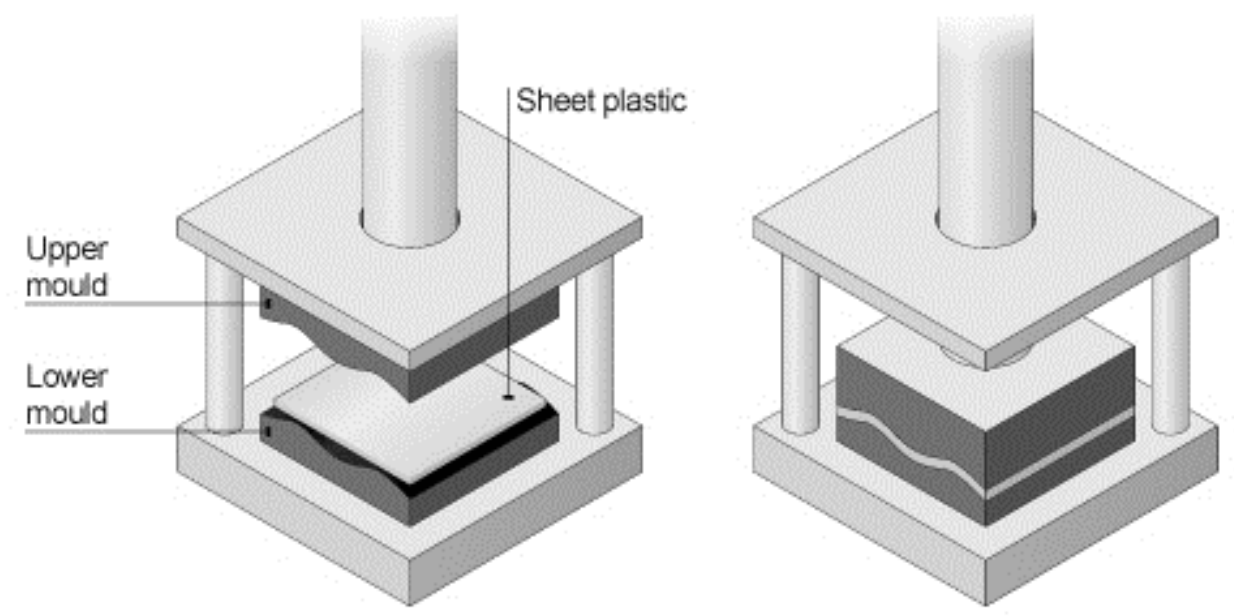

Figure 12: Press molding of thermoplastics ${ }^{20}$.

The mold can be cold or heated depending upon the thermoplastic used and the cooling rates needed. The mold is then closed on the blank and the parts takes form. Depending upon fabric 
being used variations in the amount of slip and flow occur while being pressed. This overall production cycle can form parts in two to ten minutes dramatically reducing the fabrication time when compared to thermoset composites ${ }^{6}$. This reduction in manufacturing time has made thermoplastic composites more prevalent in the high production rate industries. 


\section{CULMINATING EXPERIENCE}

This thesis experience was far from that of a conventional research or design project. Specifically, it was a six month cooperative experience at The Boeing Company in Seattle, Washington. Not only did this project integrate research and design, but it also involved business practice and industry relations- two components rarely seen in a thesis. Despite the additional complexities, research and design made up the majority of the project. Research was a key component of the project as it was necessary for materials selection, determination of mechanical properties, understanding chemistry and material interactions, as well as a significant amount of problem solving. The research went beyond a single topic of study and developed into a complete system design. In such a system, use of one material and one process is simply not enough to design a functional structure that can fly. Only after conducting the proper research and integrating it with existing and practical knowledge, the final system was designed, fabricated, and approved for flight.

\section{A. COMPOSITE FABRICATION AND LABORATORY EXPERIENCE}

During my co-op at Boeing I developed an in-depth understanding of thermoplastic processing and fabrication. This development of processing skills included many of the processing methods discussed earlier in this report. Because thermoplastics are processed at higher temperatures than thermoset composites, care had to be taken to use proper high temperature consumable materials and handling methods. Different processing parameters were chosen for optimization. To determine which processing type and parameters were chosen, DSC testing and FTIR was done to determine crystallinity, glass transition temperature, and heats of fusion. With a basic understanding of the relationship between processing and chemistry the 
most efficient and optimal methods were chosen. Through the processing of such composites I was able to utilize autoclaves, ovens, presses, molds, unique bagging materials, and new materials currently in development. Being able to handle and utilize materials still being considered and developed was a unique experience. Knowing that I was able to work with materials new to the market added to the uniqueness of this experience.

Upon learning the unique characteristics of thermoplastics and how to process them, mechanical testing was conducted to determine specific properties for each design application. I was able to witness unique testing techniques similar to the ASTM specifications mentioned previously. Having the ability to choose the testing required, understanding the data gathered, and being able to form conclusions based upon the data are critical skills for moving forward with any future endeavors. I learned new imaging techniques commonly used for composite parts and was able to analyze outputs and determine part performance. Not only were basic mechanical property tests conducted, but proof of concept and design tests were completed as well. These proof of design tests were not only interesting to witness, but were a confirmation of the decisions made throughout the course of the project.

\section{B. INDUSTRY EXPERIENCE}

Throughout the course of this project I gained access to a professional network of dedicated engineers with irreplaceable backgrounds. Being able to learn from experts in their respective fields was a remarkable experience. Not only did I learn about new concepts, I was able to develop new skills. Attending meetings and presenting projects and updates were important in increasing my public speaking abilities and my ability to prepare presentation materials. Throughout the co-op I was held accountable for several technical documents including 
summaries of testing conducted, as well as a design report that detailed the entirety of a part design. 


\section{BIBLIOGRAPHY}

${ }^{1}$ Mallick, P. (2008). Fiber-Reinforced Composites- Materials, Manufacturing, and Design. Boca Raton: CRC Press.

${ }^{2}$ Corporation, F. G. (2013). Kevlar, Carbon, Glass. Retrieved from Fibre Glast: http://www.fibreglast.com/product

${ }^{3}$ Bunsell, A. (1988). Fibre Reinforcements for Composite Materials. Amsterdam: Elsevier Science.

${ }^{4}$ Velasco, R. A. (2005). Germal Wool Fabric and Manufacturing of World War Two. Retrieved from Lost Battalions: http://www.lostbattalions.com/Resources/RayonArticle.html

5 Zoltek. (2013). Panex 35 Prepreg Tapes. Retrieved from Zoltek- Commercial Carbon Fiber: http://www.zoltek.com/products/panex-35/prepreg/

${ }^{6}$ Strong, A. B. (2008). Fundamentals of Composites Manufacturing Materials, Methods, and Applications. Dearborn: Society of Manufactuing Engineers.

${ }^{7}$ Jones, R. M. (1999). Mechanics of Composite Materials. New York: Taylor \& Francis Group, LLC

${ }^{8}$ Farag, M. M. (2008). Materials and Process Selection for Engineering Design. Boca Raton: CRC Press.

${ }^{9}$ ASTM. (2011). Standard Test Method for Tensile Properties of Polymer Matrix Composite Materials. In ASTM., Annual Book of ASTM Standards (pp. 1-313. West Conshohocken: ASTM International. 
${ }^{10}$ ASTM. (2004). Standard Test Method for Flexural Properties of Unreinforced and Reinforced Plastics and Electrical Insulating Materials. In ASTM, Annual Book of ASTM Standards (pp. 1-9). West Conshohocken: ASTM International.

${ }^{11}$ ASTM. (2011). Standard Test Method for Mode I Fatigue Delamination Growth Onset of Unidirectional Fiber-Reinforced Polymer Matrix Composites. In ASTM., Annual Book of ASTM Standards (pp. 1-6). West Conshohocken: ASTM International.

${ }^{12}$ ASTM. (2006). Standard Test Method for Mode I Interlaminar Fracture Toughness of Unidirectional Fiber- Reinforced Polymer Matrix Composites. In ASTM, Annual Book of ASTM Standards (pp. 1-13). West Conshohocken: ASTM International.

${ }^{13}$ ASTM. (2012). Standard Practic for Ultrasonic Testing of Flat Panel Composites and Sandwich Core Materials Used in Aerospace Applications1. In ASTM, Annual Book of ASTM Standards (pp. 1-7). West Conshohocken: ASTM International.

${ }^{14}$ Gharda, K. H. (2005). United States Patent No. 6881816.

${ }^{15}$ Hill, H. E. (2013). Nucleophilic Aromatic Substitution. Retrieved from Supplementary Topic: http://highered.mcgraw-hill.com/sites/dl/free/

${ }^{16}$ Harris, L. (2011). A Study of the Crystallization Kinetics in PEEK and PEEK Composites. Edgbaston: The University of Birmingham.

${ }^{17}$ Sichina, W. (2000). DSC as Problem Solving Tool: Measurement of Percent Crystallinity of Thermoplastics. Norwalk: Perkin Elmer Instruments.

${ }^{18}$ Plastics, I. (2014). Heat of Fusion/Crystallization/Melting Point and Glass Transition by Differential Scanning Calorimeter. Pittsfield, Maine, United States of America. 
${ }^{19}$ Kalpakjian, S., \& Schmid, S. R. (2008). Manufacturing Processes for Engineering Materials. Upper Saddle River, New Jersey: Pearson Enducation, Inc.

${ }^{20}$ Bitesize, BBC. (2014). Production Technologies: Shaping by Deforming Plastics. Retrieved from Topic: http://www.bbc.co.uk/schools/gcsebitesize/design/resistantmaterials/ processtechniquesrev7.shtml 